\title{
The antitumor effects of arsenic trioxide in mantle cell lymphoma via targeting Wnt/ $\beta$-catenin pathway and DNA methyltransferase-1
}

\author{
XIN-YU LI, YING LI, LINGYAN ZHANG, XIN LIU, LILI FENG and XIN WANG \\ Department of Hematology, Shandong Provincial Hospital Affiliated \\ to Shandong University, Jinan, Shandong 250021, P.R. China
}

Received March 23, 2017; Accepted August 17, 2017

DOI: $10.3892 /$ or.2017.5945

\begin{abstract}
Mantle cell lymphoma (MCL) is an aggressive non-Hodgkin lymphoma (NHL) with poor prognosis. The rapid progression and frequently relapse make it urgent to identify therapeutic agents with potent antitumor effect. Increasing evidence indicated that dysregulation of Wnt/ $\beta$-catenin pathway and abnormal methylation appeared to promote tumorigenesis. Arsenic trioxide $\left(\mathrm{As}_{2} \mathrm{O}_{3}, \mathrm{ATO}\right)$ has been reported effective in many hematologic malignancies in recent studies, however, the mechanism and effects of ATO in MCL still need further research. In this study, ATO was shown to promote apoptosis and to inhibit cell viability in MCL cell lines, whereas, the expression of DNA methyltransferase-1 (DNMT-1), $\beta$-catenin and the downstream molecules of Wnt/ $\beta$-catenin pathway such as c-myc, cyclin D1 and MMP7 were all decreased in a dose-dependent manner with ATO. ATO also attenuated upregulation of $\beta$-catenin after $\mathrm{LiCl}$ stimulation and provided synergistic effect with 5-azacytidine (5-azaC) on the DNMT-1 inhibition. The results indicated that ATO may suppress MCL by targeting Wnt/ $\beta$-catenin pathway and DNMT-1. These findings may guide drug usage of ATO in clinical therapy for MCL.
\end{abstract}

\section{Introduction}

Mantle cell lymphoma is an aggressive mature B-cells derived non-Hodgkin lymphoma (NHL) with genetic hallmark of translocation $\mathrm{t}(11 ; 14)(\mathrm{q} 13 ; \mathrm{q} 32)$, resulting in overexpression of

Correspondence to: Dr Xin Wang, Department of Hematology, Shandong Provincial Hospital Affiliated to Shandong University, 324 Jingwu Road, Jinan, Shandong 250021, P.R. China

E-mail: xinw007@126.com

Abbreviations: MCL, mantle cell lymphoma; ATO, arsenic trioxide; APL, acute promyelocytic leukemia; DNMT-1, DNA methyltransferase-1; 5-azaC, 5-azacytidine

Key words: arsenic trioxide, Wnt/ $\beta$-catenin pathway, DNA methyltransferase-1, mantle cell lymphoma cyclin D1 (1). Most of MCL patients have an aggressive clinical behavior and poor survival rates. However, the potent and effective therapeutic agents are still lacked. The Wnt/ $\beta$-catenin pathway is responsible for growth and development in normal cells, constitutively activation of $\mathrm{Wnt} / \beta$-catenin pathway was demonstrated in MCL and appeared to promote tumorigenesis (2). With the dysregulation of Wnt inhibitory factors and inactivation of GSK3 $\beta$, $\beta$-catenin accumulated in the cytoplasm and translocated to the nucleus, in which it promotes transcription of downstream target genes including cyclin D1 that could contribute to oncogenesis (3). Moreover, there is a growing body of evidence that abnormal epigenetic regulations occur in the hematological diseases (4), methyltransferase-1 (DNMT-1) has become a highlight of the methylation study. Recent studies suggest that magnitude of DNA methylation variations could be used as an independent prognostic factor for MCL prognosis (5). It is interesting to note that promoter methylation was reported to be responsible for the silence and dysregulation of Wnt inhibitory factors and a certain number of tumor suppressor genes (6).

Arsenic derivatives were first used as therapeutic compounds or poison in ancient Greek and China (7). In the 1990s, clinical trails in acute promyelocytic leukemia (APL) with pure arsenic trioxide (ATO) demonstrated complete remission was achieved in $66 \%$ patients with a survival rate of $60 \%$ at 7 years (8). It is noteworthy that ATO and oral trans- retinoic acid (ATRA) combination has been the standard of care for patients with non-high-risk APL that were newly diagnosed (9). The therapeutic potential of ATO has also been developed in many other hematologic malignancies. Although disappointing results were identified in elderly patients with acute nonpromyelocytic leukemia (ANPL) who were tested with ATO alone or in combination with other agents (10), recent reports suggested that ATO and ATRA combination may be a potential treatment for AML patients with NPM1 (11). Two multicenter trails also evaluated ATO usage in patients with MDS and provided evidence for ATO activity in MDS treatment depending on the risk group (12). A randomized phase 2 trail manifested that the combination of ATO and bortezomib was safe and well-tolerated in multiple myeloma patients (13). However, there are rare reports on the effects and mechanism of ATO used in mantle 
cell lymphoma. In this study, we investigated the mechanism of ATO especially the effect on $\mathrm{Wnt} / \beta$-catenin pathway and DNMT-1 in MCL and aimed to provide better treatment options for MCL patients.

\section{Materials and methods}

Ethics statement. The study was approved by the Medical Ethical Committee of the Provincial Hospital Affiliated to Shandong University. All human samples were obtained after informed consents had been given, according to the Declaration of Helsinki.

Antibodies and regents. Primary rabbit antibody against $\beta$-catenin (D10A8), c-Myc (D3N8F) and DNMT-1 (D63A6) were obtained from Cell Signaling Technology (Danvers, MA, USA). GAPDH was purchased from Zhongshan Goldenbridge (ZSGB-BIO, Beijing, China). ATO was purchased from Yida Medicine Co. (Haerbin, China), $\mathrm{LiCl}$ was from Sigma-Aldrich (Sigma, St. Louis, MO, USA), 5-azacytidine (5-azaC) was also from Sigma-Aldrich.

Cell culture and treatments. Human MCL cell lines Jeko-1, Mino, SP53 and Grant519 were used in the present study. Unless otherwise specified, Jeko-1, Mino, SP53 and Grant519 were cultured in RPMI-1640 (Gibco, Grand Island, NY, USA) with $10 \%$ fetal calf serum (FBS, Hyclone, Logan, UT, USA) maintained at $37^{\circ} \mathrm{C}$ in $5 \%$ carbon dioxide. Jeko-1 was purchased from Cell Bank of Chinese Academy of Sciences (Shanghai, China). Mino, SP53 and Grant519 were kind gifts from Dr Michael Wang (Department of Lymphoma and Myeloma, the University of Texas MD Anderson Cancer Center, Houston, TX, USA). All cells were cultured with the needed concentrations of ATO, $\mathrm{LiCl}, 5$-azaC for necessary time, and the medium was changed every $48 \mathrm{~h}$. Peripheral blood from healthy volunteers was collected by heparin anticoagulation and then peripheral blood mononuclear cells (PBMCs) were separated by Ficoll-Hypaque density gradient centrifugation method (TBD Science, Tianjin, China) and used as normal control.

Protein extraction and western blot analyses. Total protein was extracted from cell lines, PBMCs by using RIPA and 1\% PMSF (Shenergy Biocolor, China). BCA assay (Shenergy Biocolor) was used to measure the concentrations of total protein according to the manufacturer's instructions. Electrophoresis was performed on 5 or $10 \%$ sodium dodecyl sulfate-polyacrylamide gel electrophoresis (SDS-PAGE) with $30 \mu \mathrm{g}$ total protein, and then the protein was transferred on polyvinylidene difluoride (PVDF) membranes. After incubated with $10 \%$ milk for $1 \mathrm{~h}$ in room temperature, the membranes were covered with primary antibodies at $4^{\circ} \mathrm{C}$ overnight. All of the primary antibodies were used at 1:1,000 dilution. After one hour incubation with anti-rabbit/mouse IgG horseradish peroxidase (HRP) conjugated antibodies, immunodetection was done with enhanced chemiluminescence detection kit (Millipore, Billerica, MA, USA). GAPDH was used as the loading control. Protein bands were detected by laser densitometry and analyzed by Multi Gauge Ver.4.0 software (Fujifilm Life Science, Japan).
Table I. Primer sequences.

Gene

Primer sequences

Cyclin D1-F

5'-CAAATGGAGCTGCTCCTGGTG-3'

Cyclin D1-R

5'-CTTCGATCTGCTCCTGGCAGG-3'

MMP7-F

5'-AGATGTGGAGTGCCAGATGT-3'

MMP7-R

5'-TAGACTGCTACCATCCGTCC-3'

$\beta$-actin-F 5'-TGACGTGGACATCCGCAAAG-3'

$\beta$-actin-R 5'-CTGGAAGGTGGACAGCGAGG-3'

Immunohistochemistry analysis. Twenty cases of human MCL lymph nodes tissue and 15 cases of reactive hyperplasia of lymph node tissues embedded by paraffin were enrolled in the present study. All of the lymph node tissue samples detected were obtained from patients who attended Shandong Provincial Hospital Affiliated to Shandong University (Shandong, China) from 2010 to 2016. MCL diagnosis was based on established clinical criteria (14). Paraffin-embedded tissue sections were processed and incubated with primary antibodies at 1:100 dilution overnight, PBS were used in negative controls sections instead. After incubation with the second antibody which was purchased from SP reagent kit (Zhongshan Goldenbridge Biotechnology Company, Beijing, China). Five high-power fields were randomly captured at $\times 400$ magnification. According to the proportion of positively stained tumor cells, tumors displaying staining in $30 \%$ or more of the cells were categorized as positive, on the contrary, were categorized as negative.

Cell viability and apoptosis assay. Cell Counting Kit-8 (CCK8; EnoGene, China) was utilized to detect the viability of cells. Cells $\left(5 \times 10^{4}\right) / 100 \mu 1$ were seeded into each well of the 96 -well plates and treated with necessary concentrations of ATO for $24 \mathrm{~h}$, and then the cells were incubated with $10 \mu \mathrm{l} \mathrm{CCK} 8$ at $37^{\circ} \mathrm{C}$ for $4 \mathrm{~h}$. The absorbance at $450 \mathrm{~nm}$ was measured with a SpectraMax M2 Multi-Mode Microplate Reader (Molecular Devices, Sunnyvale, CA, USA).

An amount of $1 \times 10^{6}$ cells treated with different concentrations of ATO were stained with Annexin V-FITC and PI for $15 \mathrm{~min}$ at room temperature in the dark, and then immediately analyzed with FACScan flow cytometer (Beckman Coulter, Chicago, IL, USA). The data were analyzed with FlowJo Version 7.6 software (Tree Star Inc., Ashland, OR, USA).

RNA extraction and quantitative real-time PCR ( $q R T-P C R)$. Total RNA was extracted from cell lines with TRIzol reagent (Takara, Dalian, China), PrimeScript RT reagent kit (Takara) was used to conduct reverse transcription of complementary DNA (cDNA) according to the manufacturer's instructions. Amplification reaction was performed on LightCycler 480 real-time PCR system (Roche Dignostics, Mannheim, Germany). Data were analyzed by using the $2^{-\Delta \Delta \mathrm{Ct}}$ method with LightCycler 480 Gene Scanning Version 1.5 Software (Roche Diagnostics). Actin was used as an internal control, the primer sequences are listed in Table I.

Statistical analysis. Statistics was analyzed by SPSS (version 17.0, SPSS, Chicago, IL, USA) for windows. Data 
A

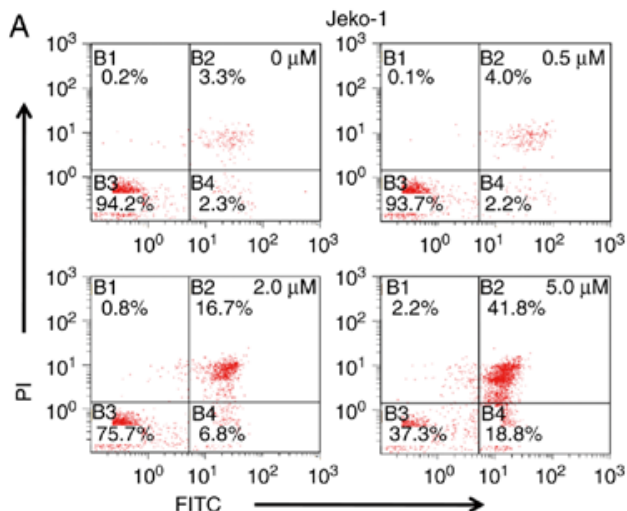

C

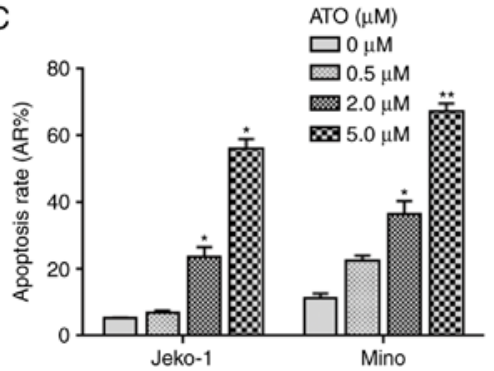

B
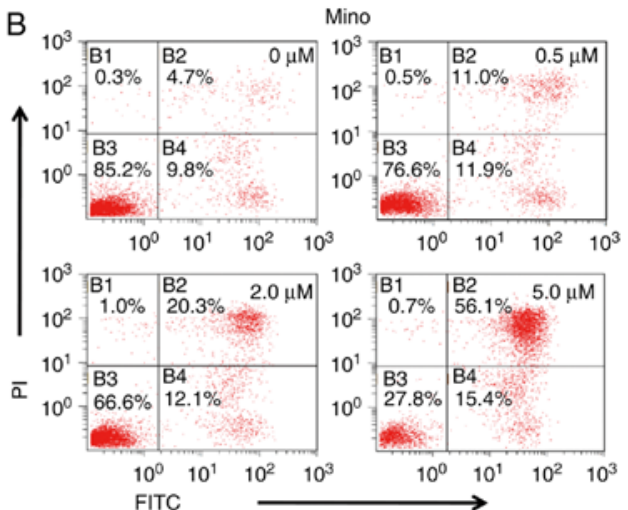

D

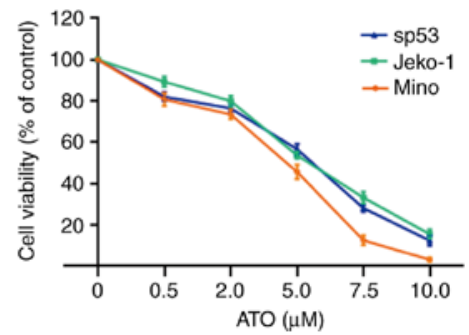

Figure 1. ATO promotes cell apoptosis and inhibits cell viability. (A and B) Apoptosis rates of Jeko-1 (A) and Mino (B) cells treated with ATO in gradient concentrations $(0,0.5,2.0$ and $5 \mu \mathrm{M})$ for $24 \mathrm{~h}$ were quantified by flow cytometry. (C) Statistical analysis of (A) and (B). Solvent group served as control, Student's t-test, ${ }^{* *} \mathrm{P}<0.01,{ }^{*} \mathrm{P}<0.05$. (D) After MCL cell lines Jeko-1, Mino and SP53 were cultivated with ATO for $24 \mathrm{~h}$ in gradient concentration (0, 0.5, 2.0, 5.0, 7.5 and $10.0 \mu \mathrm{M})$, the viability of the cells was evaluated by CCK-8 assay. Data represent the mean \pm SD from three independent experiments.

represent the mean from at least three independent experiments for all results. Kaplan-Meier method was used for survival analysis. Data which complied with normal distribution were expressed as mean \pm standard deviation (SD). The numerical data were statistically analyzed by Student's t-test. $\mathrm{P}<0.05$ was considered statistically significant.

\section{Results}

ATO promotes cell apoptosis and inhibits cell viability. To elucidate the effects of ATO in MCL, the apoptosis rate of MCL cell lines (Jeko-1 and Mino) treated with ATO $(0,0.5$, 2.0 and $5.0 \mu \mathrm{M}$ ) for $24 \mathrm{~h}$ was measured by flow cytometry. Significant increase of apoptosis rates were detected in Jeko-1 and Mino cells with higher concentrations of ATO (Fig. 1A-C, $\mathrm{P}<0.05)$ compared with $0.5 \mu \mathrm{M}$ ATO-treated group. Early apoptosis rates in the two cell lines increased slightly with higher concentrations of ATO, however, the increasement of late apoptotic cells was more remarkable. Moreover, the CCK8 assay was performed on MCL cell lines Jeko-1, Mino and SP53. As shown in the figure, the viability of cells was notably inhibited by ATO with increased concentrations $(0,0.5,2.0$, 5.0, 7.5 and $10.0 \mu \mathrm{M}$ ) (Fig. 1D). In conclusion, these data manifested that ATO treatment induced MCL apoptosis and inhibited cell viability in a dose-dependent manner.

Wnt/ $\beta$-catenin pathway is active and DNMT-1 is upregulated in $M C L$. As the dysregulation of $\mathrm{Wnt} / \beta$-catenin pathway could promote lymphomagenesis, we examined the protein expression of $\beta$-catenin, which is the core molecule of the $\mathrm{Wnt} / \beta$-catenin pathway, and the downstream molecule c-Myc
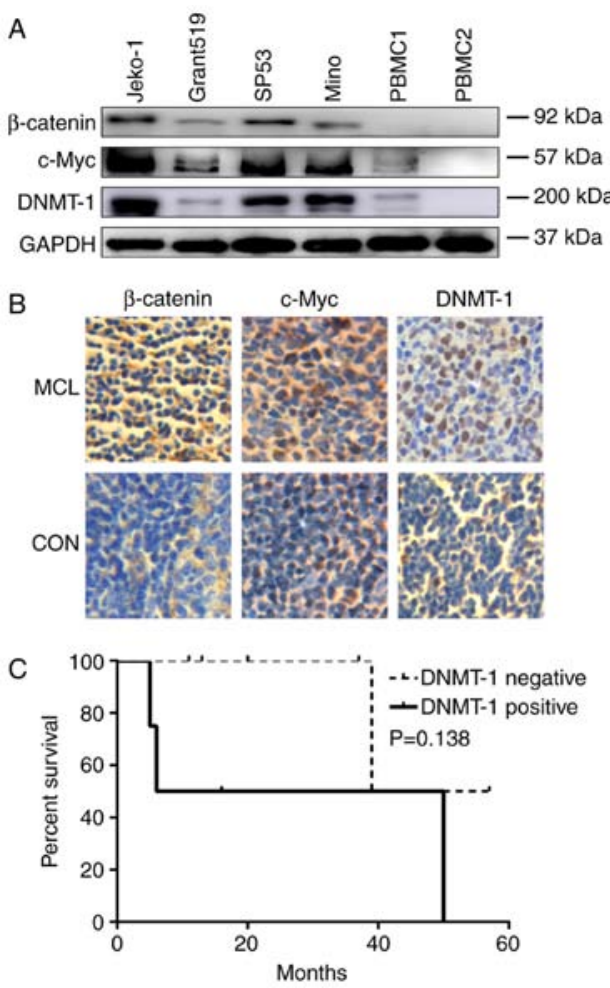

Figure 2. Wnt/ $\beta$-catenin pathway is active and DNMT-1 is upregulated in MCL. (A) Protein expression of $\beta$-catenin (92 kDa), c-myc $(57 \mathrm{kDa})$ and DNMT-1 (200 kDa) were detected in the MCL cell lines and PBMCs, GAPDH was used as loading control by western blotting. (B) Expression of $\beta$-catenin, c-myc and DNMT-1 in MCL and reactive hyperplasia of lymph node tissues (control) were detectd by immunohistochemistry analysis. Original magnification, $x$ 400. (C) The survival analysis of MCL patients. DNMT- $1^{+}$means positive expression of DNMT-1 in tissues dectected by immunohistochemistry analysis, similarly, DNMT-1 ${ }^{-}$means negative expression. 

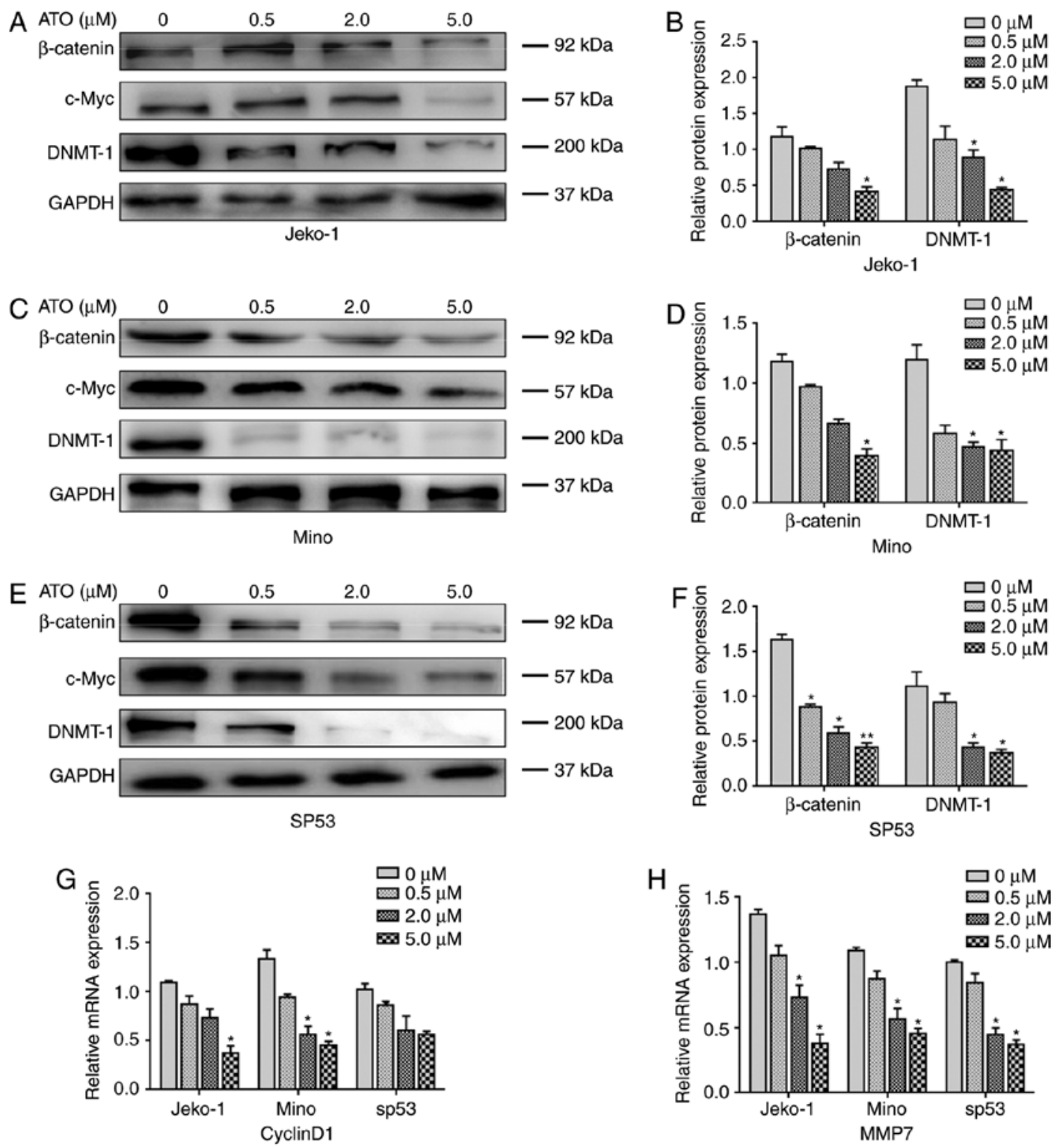

Figure 3. ATO supresses Wnt/ $\beta$-catenin pathway and DNMT-1 in MCL. (A-F) After cultivated with ATO for 48 h in gradient concentration (0, $1.0,2.0$ and $5.0 \mu \mathrm{M}$ ), protein expressions of $\beta$-catenin, c-Myc and DNMT-1 in MCL cell lines Jeko-1 (A), Mino (C) and SP53 (E) were assayed by western blotting. (B, D and F) Statistical analysis of (A), (C) and (E). Solvent group served as control, Student's t-test, ${ }^{* *} \mathrm{P}<0.01,{ }^{*} \mathrm{P}<0.05$. (G and H) After cultivated with ATO for $48 \mathrm{~h}$ in gradient concentration $(0,1.0,2.0$ and $5.0 \mu \mathrm{M})$, mRNA expression of cyclin D1 and MMP7 in MCL cell lines Jeko-1, Mino and SP53 were quantified by qRT-PCR. Solvent group served as control, Student's t-test, ${ }^{*} \mathrm{P}<0.05$. Data represent the mean \pm SD from three independent experiments.

in MCL. In MCL cell lines Jeko-1, Grant519, SP53 and Mino, the expression of $\beta$-catenin and c-Myc in all cell lines were notably higher compared with PBMCs from healthy volunteers (Fig. 2A). Furthermore, the conclusion was also confirmed in MCL tissue samples by immunohistochemical staining (Fig. 2B).

Recent reports also indicated that methylation related silence of Wnt inhibitory factors contributed to the activation the Wnt/ $\beta$-catenin pathway (6), we also showed that protein expression of DNMT-1 in MCL cell lines and MCL patients' lymphoma tissues were extremely higher than PBMCs from healthy volunteers and reactive hyperplasia of lymph node tissues manifested by western blot analysis and immunohistochemical staining, respectively (Fig. 2A and B). The upregulation of DNMT-1 further reduced expression of tumor suppressor genes which in turn contributed to tumorigenesis. In our follow-up and survival analysis, we found that the survival rate of MCL patients with negative DNMT-1 expression was higher than the postive expression group before 39 months according to the survival curve, although the expression of DNMT-1 was not closely associated with MCL patients' prognosis (Fig. 2C, P>0.05).

ATO suppresses Wnt/ $\beta$-catenin pathway in MCL. To explore the inhibition mechanism of ATO in MCL, we investigated the effect of ATO on Wnt/ $\beta$-catenin pathway and DNMT-1 which were demonstrated upregulated in MCL. The protein expression of $\beta$-catenin and c-myc were found decreased with the increased concentrations of ATO $(0,0.5,2.0$ and $5.0 \mu \mathrm{M})$ for $24 \mathrm{~h}$ in Jeko-1, Mino and SP53 cells (Fig. 3A-F, P<0.05). We further investigated cyclin D1 and MMP7, the downstream molecules of the Wnt/ $\beta$-catenin pathway, were all decreased 
A

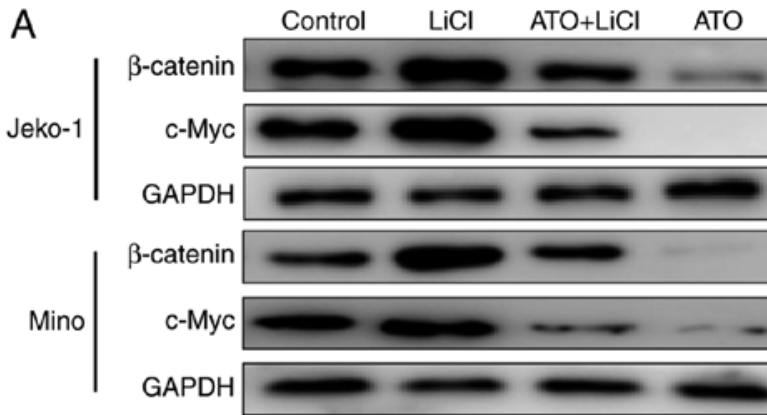

D

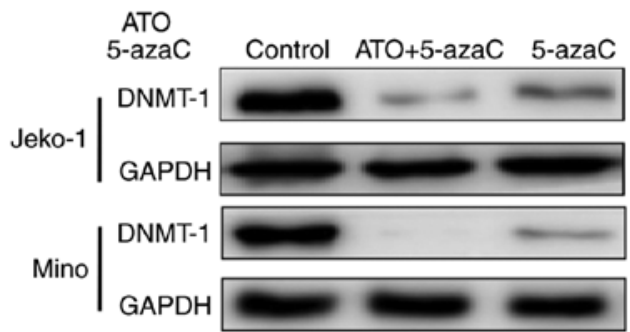

E

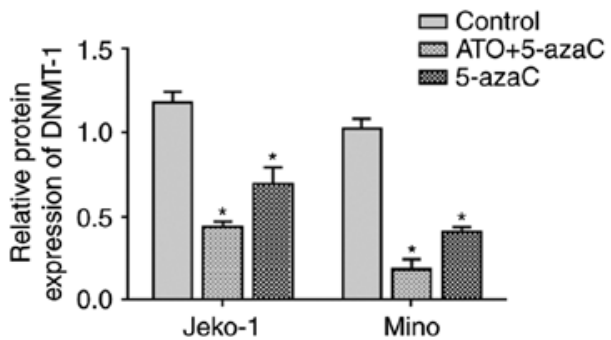

B

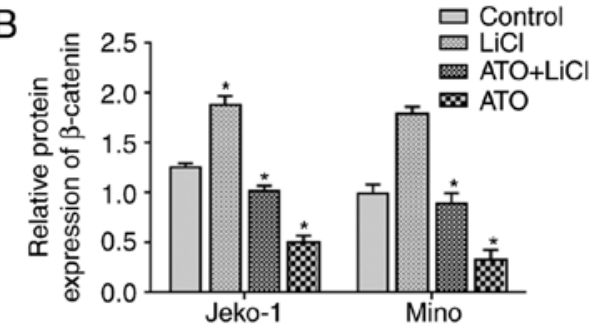

C

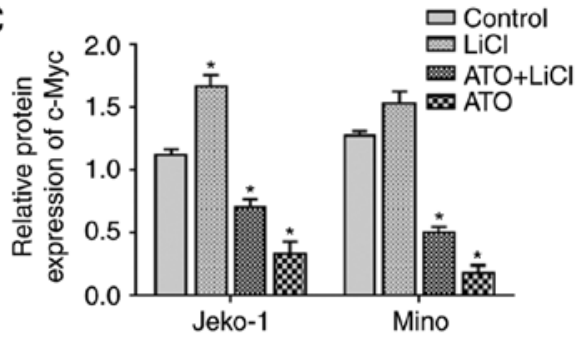

F

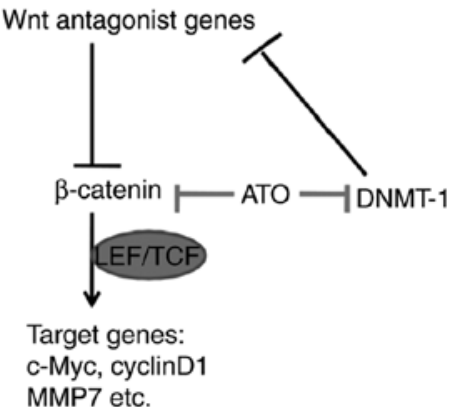

Figure 4. ATO attenuates upregulation of $\beta$-catenin after $\mathrm{LiCl}$ stimulation and provided synergistic effect with 5-azaC on the DNMT-1 inhibition. (A) LiCl $(10 \mu \mathrm{M})$ and ATO $(2.0 \mu \mathrm{M})$ were used alone or together in Jeko-1 and Mino cells as indicated in the figure for $48 \mathrm{~h}$, and then the protein expression of $\beta$-catenin and c-Myc were detected by western blotting. (B and C) Statistical analysis of (A). Solvent group served as control, Student's t-test, "P<0.05. (D) 5-AzaC $(2.0 \mu \mathrm{M})$ and ATO $(2.0 \mu \mathrm{M})$ were used alone or together in Jeko-1 and Mino cells as indicated in the figure for $48 \mathrm{~h}$, and then the protein expression of DNMT-1 were detected by western blotting. (E) Statistical analysis of (D). Solvent group served as control, Student's t-test, ${ }^{*} \mathrm{P}<0.05$. Data represent the mean \pm SD from three independent experiments. (F) The illustration of mechanism of antitumor effect of ATO is indicated in this study. ATO could inhibit Wnt/ $\beta$-catenin pathway and DNMT-1, however, the inhibition of DNMT-1 could promote reexpression of methylated Wnt inhibitor, suppressing Wnt/ $\beta$-catenin pathway.

in a dose-dependent manner with ATO in the transcript level (Fig. 3G and $\mathrm{H}, \mathrm{P}<0.05$ ). In addition, to verify the suppression effect on $\mathrm{Wnt} / \beta$-catenin pathway of $\mathrm{ATO}, \mathrm{LiCl}$ which is a classical activator of $\mathrm{Wnt} / \beta$-catenin pathway was added. However, ATO attenuated upregulation of $\beta$-catenin and c-myc expression after $\mathrm{LiCl}$ stimulation in MCL cell lines (Fig. 4A-C, $\mathrm{P}<0.05)$.

ATO inhibits DNMT-1 expression in MCL. The western blot analysis showed that the protein expression of DNMT-1 was also downregulated by ATO in a dose-dependent manner $(0,0.5,2.0$ and $5.0 \mu \mathrm{M})$ in MCL cell lines Jeko-1, Mino and SP53 (Fig. 3A-F, P<0.05). The combination of ATO and demethylation agent 5 -azaC was more potent than 5-azaC used alone in the inhibition of DMNT-1 expression (Fig. 4D and E, $\mathrm{P}<0.05)$.

\section{Discussion}

In this study, we demonstrated that ATO could promote apoptosis and inhibited cell viability in MCL cell lines. Wnt/ $\beta$-catenin pathway and DNMT-1 were constitutively activated in MCL, however, the expression of DNMT-1, $\beta$-catenin and the downstream molecules of $\mathrm{Wnt} / \beta$-catenin pathway such as c-myc, cyclin D1 and MMP7 were all downregulated in a dose-dependent manner with the treatment of ATO. ATO also attenuated upregulation of $\beta$-catenin after $\mathrm{LiCl}$ stimulation and provided synergistic effect with 5 -azaC on the DNMT-1 inhibition. Our results indicated that ATO suppressed MCL by targeting Wnt/ $\beta$-catenin pathway and DNMT-1. These findings may provide better treatment options for MCL patients (Fig. 4F).

ATO has been found effective in solid tumors and hematologic malignancies, studies revealed ATO interacts with multiple molecules and signaling pathways $(15,16)$. In APL, at lower concentrations $(0.1-0.5 \mu \mathrm{M})$, ATO promotes differentiation; however, it induces apoptosis at higher concentrations $(0.5-2.0 \mu \mathrm{M})(8)$. The apoptosis effect of ATO is associated with targeting and inducing degradation of the PML-RAR $\alpha$ protein and downregulation of human telomerase gene (17). It is underlined that significant increase of apoptosis rates and inhibition of cell viability were also detected in Jeko-1 and Mino cells with high concentrations of ATO compared with $0.5 \mu \mathrm{M}$ ATO-treated group in our result. ATO also has 
a promising role in relapsed multiple myeloma (13). Previous studies showed that ATO could inhibit capillary tubule growth and vessel branching by reducing VEGF production (18). A report from Zhou et al (19) indicated that ATO can decrease the expression of $\beta$-catenin and induce synergic activity with Bortezomib in multiple myeloma.

Activated Wnt/ $\beta$-catenin pathway is a crucial pathway for leukemic transformation, proliferation and survival (20). Previous reports mentioned constitutively activation of the pathway and upregulation of signaling molecules such as Wnt3 and Wnt10 in MCL $(2,21)$. Consistent with the previous investigation, our results manifested enhancement of $\beta$-catenin and c-myc in the MCL cell lines and MCL patients' lymph tissues. The expression of $\beta$-catenin and the downstream molecules such as c-myc, cyclin D1 and MMP7 which are associated with cell proliferation, cell cycle and invasion were all downregulated in a dose-dependent manner with ATO. The upregulation of $\beta$-catenin after $\mathrm{LiCl}$ stimulation was also attenuated by ATO in MCL cell lines. Zheng et al also considered ATO probably inhibited the Wnt/ $\beta$-catenin pathway through demethylating and reactivating the Wnt inhibitor, SFPR1 (22). Our result showed that DNMT-1 was inhibited by ATO in a dose-dependent manner in MCL lines. DNMT-1, DNMT-3a and DNMT3b are important methyltransferases for the establishment and maintenance of DNA methylation status (23). DNMT-1 is responsible for the maintenance of established DNA methylation patterns (24). Recent findings indicated that ATO was catalyzed and converted into methylated products and then produced S-adenosylhomocysteine which could bring about DNA hypomethylation in liver and a small part in kidney and lung, however, the process utilized $\mathrm{S}$-adenosylmethionine which is an essential co-factor of DNMTs, so that ATO participated in the regulation of the methylated tumor suppressor genes by direct inhibiting DNMTs and a depletion of the methyl donor (25). The tumor suppressor genes demethylated by ATO may perform function by targeting signaling pathways such as $\mathrm{Wnt} / \beta$-catenin pathway. Furthermore, our follow-up and survival analysis indicated that the survival rate of MCL patients with negative DNMT-1 expression was higher than the positive expression group before 39 months. The combination of ATO and demethylation agent 5-azaC was more effective than 5-azaC used alone in the inhibition of DMNT-1 expression. It is known that 5-azaC exerts a hypomethylating role in low concentration but a cytotoxic activity with high concentration. The synergistic effect of ATO with 5-azaC on the DNMT-1 inhibition suggested it may be an efficient therapeutic strategy in MCL.

In conclusion, this study indicated that ATO has an anticancer effect on MCL by targeting Wnt/ $\beta$-catenin pathway and DNMT-1. The synergistic effect of ATO and other agents such as 5-azaC may guide drug usage of ATO in clinical therapy for MCL. However, the mechanism and unique metabolism of ATO still need further research to explore its potential.

\section{Acknowledgements}

This study was supported in part by: National Natural Science Foundation (nos. 81473486 and 81270598), National Public Health Grand Research Foundation (no. 201202017), Natural
ScienceFoundations ofShandongProvince(nos.ZR2012HZ003 and 2009ZRB14176), Technology Development Projects of Shandong Province (nos. 2014GSF118021 and 2010GSF10250, and no. 2008GG2NS02018), Program of Shandong Medical Leading Talent, and Taishan Scholar Foundation of Shandong Province.

\section{References}

1. Lu K, Chen N, Zhou XX, Ge XL, Feng LL, Li PP, Li XY, Geng LY and Wang X: The STAT3 inhibitor WP1066 synergizes with vorinostat to induce apoptosis of mantle cell lymphoma cells. Biochem Biophys Res Commun 464: 292-298, 2015.

2. Gelebart P, Anand M, Armanious H, Peters AC, Dien Bard J, Amin HM and Lai R: Constitutive activation of the Wnt canonical pathway in mantle cell lymphoma. Blood 112: 5171-5179, 2008

3. Hoffmeyer K, Raggioli A, Rudloff S, Anton R, Hierholzer A, Del Valle I, Hein K, Vogt $\mathrm{R}$ and Kemler R: Wnt/ $\beta$-catenin signaling regulates telomerase in stem cells and cancer cells. Science 336: 1549-1554, 2012.

4. Wang LQ, Wong KY, Rosèn A and Chim CS: Epigenetic silencing of tumor suppressor miR-3151 contributes to Chinese chronic lymphocytic leukemia by constitutive activation of MADD/ERK and PIK3R2/AKT signaling pathways. Oncotarget 6: 44422-44436, 2015.

5. Queirós AC, Beekman R, Vilarrasa-Blasi R, Duran-Ferrer M, Clot G, Merkel A, Raineri E, Russiñol N, Castellano G, Beà S, et al: Decoding the DNA methylome of mantle cell lymphoma in the light of the entire B cell lineage. Cancer Cell 30: 806-821, 2016.

6. Wang L, Shalek AK, Lawrence M, Ding R, Gaublomme JT, Pochet N, Stojanov P, Sougnez C, Shukla SA, Stevenson KE, et al: Somatic mutation as a mechanism of Wnt $/ \beta$-catenin pathway activation in CLL. Blood 124: 1089-1098, 2014.

7. Huang A, Yue D, Liao D, Cheng L, Ma J, Wei Y, Tong A and Cheng P: Survivin T34A increases the therapeutic efficacy of arsenic trioxide in mouse hepatocellular carcinoma models. Oncol Rep 36: 3283-3290, 2016.

8. Falchi L, Verstovsek S, Ravandi-Kashani F and Kantarjian HM: The evolution of arsenic in the treatment of acute promyelocytic leukemia and other myeloid neoplasms: Moving toward an effective oral, outpatient therapy. Cancer 122: 1160-1168, 2016.

9. Lo-Coco F, Avvisati G, Vignetti M, Thiede C, Orlando SM, Iacobelli S, Ferrara F, Fazi P, Cicconi L, Di Bona E, et al; Gruppo Italiano Malattie Ematologiche dell'Adulto; GermanAustrian Acute Myeloid Leukemia Study Group; Study Alliance Leukemia: Retinoic acid and arsenic trioxide for acute promyelocytic leukemia. N Engl J Med 369: 111-121, 2013.

10. Aldoss I, Mark L, Vrona J, Ramezani L, Weitz I, Mohrbacher AM and Douer D: Adding ascorbic acid to arsenic trioxide produces limited benefit in patients with acute myeloid leukemia excluding acute promyelocytic leukemia. Ann Hematol 93: 1839-1843, 2014.

11. Martelli MP, Gionfriddo I, Mezzasoma F, Milano F, Pierangeli S Mulas F, Pacini R, Tabarrini A, Pettirossi V, Rossi R, et al: Arsenic trioxide and all-trans retinoic acid target NPM1 mutant oncoprotein levels and induce apoptosis in NPM1-mutated AML cells. Blood 125: 3455-3465, 2015.

12. Bejanyan N, Tiu RV, Raza A, Jankowska A, Kalaycio M, Advani A, Chan J, Saunthararajah Y, Mooney L, Maciejewski JP, et al: A phase 2 trial of combination therapy with thalidomide, arsenic trioxide, dexamethasone, and ascorbic acid (TADA) in patients with overlap myelodysplastic/myeloproliferative neoplasms (MDS/MPN) or primary myelofibrosis (PMF). Cancer 118: 3968-3976, 2012.

13. Sharma M, Khan H, Thall PF, Orlowski RZ, Bassett RL Jr, Shah N, Bashir Q, Parmar S, Wang M, Shah JJ, et al: A randomized phase 2 trial of a preparative regimen of bortezomib, high-dose melphalan, arsenic trioxide, and ascorbic acid. Cancer 118: 2507$2515,2012$.

14. Dreyling M, Thieblemont C, Gallamini A, Arcaini L, Campo E, Hermine O, Kluin-Nelemans JC, Ladetto M, Le Gouill S, Iannitto E, et al: ESMO Consensus conferences: guidelines on malignant lymphoma. part 2: marginal zone lymphoma, mantle cell lymphoma, peripheral T-cell lymphoma. Ann Oncol 24: 857-877, 2013. 
15. Zhang S, Ma C, Pang H, Zeng F, Cheng L, Fang B, Ma J, Shi Y, Hong H, Chen J, et al: Arsenic trioxide suppresses cell growth and migration via inhibition of miR-27a in breast cancer cells. Biochem Biophys Res Commun 469: 55-61, 2016.

16. Zhang Z, Liu H, Zhou H, Zhu X, Zhao Z, Chi X, Shan H and Gao J: A facile route to core-shell nanoparticulate formation of arsenic trioxide for effective solid tumor treatment. Nanoscale 8: 4373-4380, 2016.

17. Chou WC, Hawkins AL, Barrett JF, Griffin CA and Dang CV: Arsenic inhibition of telomerase transcription leads to genetic instability. J Clin Invest 108: 1541-1547, 2001.

18. Roboz GJ, Dias S, Lam G, Lane WJ, Soignet SL, Warrell RP Jr and Rafii S: Arsenic trioxide induces dose- and time-dependent apoptosis of endothelium and may exert an antileukemic effect via inhibition of angiogenesis. Blood 96: 1525-1530, 2000.

19. Zhou L, Hou J, Fu W, Wang D, Yuan Z and Jiang H: Arsenic trioxide and 2-methoxyestradiol reduce beta-catenin accumulation after proteasome inhibition and enhance the sensitivity of myeloma cells to Bortezomib. Leuk Res 32: 1674-1683, 2008

20. Kühnl A, Valk PJ, Sanders MA, Ivey A, Hills RK, Mills KI, Gale RE, Kaiser MF, Dillon R, Joannides M, et al: Downregulation of the Wnt inhibitor CXXC5 predicts a better prognosis in acute myeloid leukemia. Blood 125: 2985-2994, 2015.
21. Mathur R, Sehgal L, Braun FK, Berkova Z, Romaguerra J, Wang M, Rodriguez MA, Fayad L, Neelapu SS and Samaniego F: Targeting Wnt pathway in mantle cell lymphoma-initiating cells. J Hematol Oncol 8: 63, 2015.

22. Zheng L, Jiang H, Zhang ZW, Wang KN, Wang QF, Li QL and Jiang T: Arsenic trioxide inhibits viability and induces apoptosis through reactivating the Wnt inhibitor secreted frizzled related protein-1 in prostate cancer cells. Onco Targets Ther 9: 885-894, 2016.

23. Mizuno S, Chijiwa T, Okamura T, Akashi K, Fukumaki Y, Niho Y and Sasaki H: Expression of DNA methyltransferases DNMT1, 3A, and 3B in normal hematopoiesis and in acute and chronic myelogenous leukemia. Blood 97: 1172-1179, 2001.

24. Haas BW, Filkowski MM, Cochran RN, Denison L, Ishak A, Nishitani S and Smith AK: Epigenetic modification of OXT and human sociability. Proc Natl Acad Sci USA 113: E3816-E3823, 2016.

25. Khaleghian A, Ghaffari SH, Ahmadian S, Alimoghaddam K and Ghavamzadeh A: Metabolism of arsenic trioxide in acute promyelocytic leukemia cells. J Cell Biochem 115: 1729-1739, 2014. 